\title{
RECOMBINATION IN DIPLOID VEGETATIVE CELLS OF SACCHAROMYCES CEREVISIAE
}

\author{
by \\ HERSCHEL ROMAN \\ Department of Genetics, SK-50, University of Washington \\ Seattle, Washington 98195
}

\begin{abstract}
Emil Chr. Hansen lecture delivered at the Carlsberg Laboratory on 18th June. 1980 ,
\end{abstract} at the occasion of the Alfred Benzon symposium 16 "Molecular Genetics in Yeast $\ll$.

Keywords: Gene conversion, crossing over.

\section{INTRODUCTION}

Gene conversion studies have been concerned with two problems. One is to explain how nonmendelian segregations come about, i.e., what are the molecular events that lead to their occurrence. The other is the high incidence of crossing over in regions flanking the region in which conversion is observed. Holliday (5) drew on the evidence then available to propose a molecular model that has since served as a catalyst for other explanations as new data began emerging. The data have been summarized by Fogel et al. (4). The biochemical and physical parameters that are implicit in the various molecular models are reviewed by Hotchkiss (6).

Holuiday's original proposal suggested an exchange of single strands of DNA between two homologous duplexes to account for gene con- version. A mutant site in the exchange region results in noncomplementarity of base pairs. This mismatch is corrected by a repair mechanism to restore complementarity, either to the mutant or to the wild-type allele. The failure to obtain certain types of aberrant segregation in proportions expected from a simple interpretation of the Holliday proposal cast doubt on the twin heteroduplex hypothesis, and suggested instead that a single heteroduplex in only one of the two homologs was not uncommon. MeselSON and RADDING ( $(9)$ proposed a unifying hypothesis that involves single strand transfer from one homolog to the other as a result of strand displacement to form a single region of hybrid DNA. By strand isomerization (15), and branch migration, the asymmetric phase, in which one chromatid has the single heteroduplex, becomes symmetric, with hybrid DNA in 
both chromatids. Recombination intermediates that would be expected from either the Holliday or the MESELSON-RADDING model have been visualized by electron microscopy in E. coli (12) and in Saccharomyces (1).

The second question, the high incidence of crossing over in adjacent regions, can be accomodated by both molecular models, although neither deals with specific numerical relationships. Hurst et al. (7) interpreted their data in meiosis in yeast to mean that gene conversion was accompanied by reciprocal recombination of outside markers fifty percent of the time. They therefore suggested that crossing over was a consequence of the molecular events leading to gene conversion, these events having a probability of fifty percent of recombining the outside markers (diagrammatically represented in Figure 1). It has since turned out that the $50 \%$ association was fortuitous. FoGEL et al. (4)

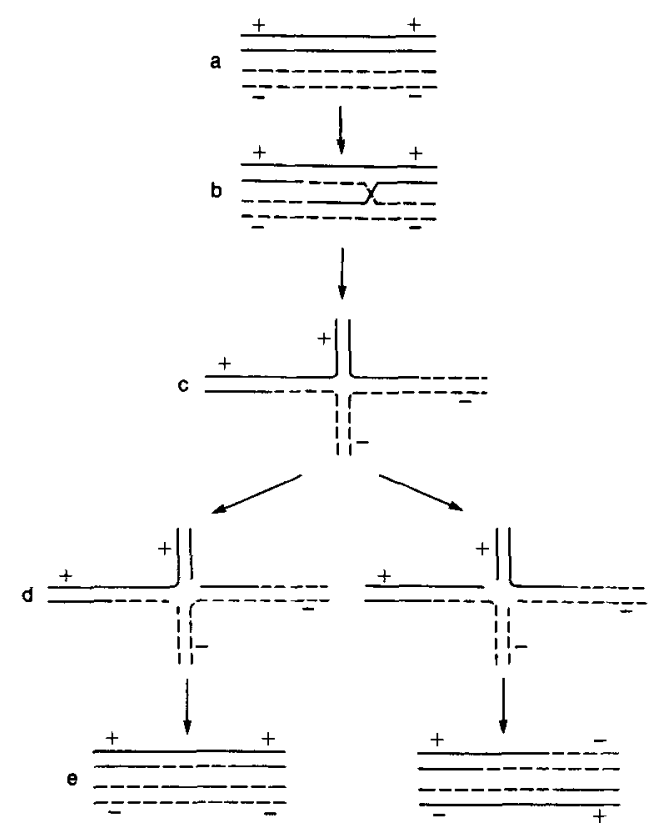

Figure 1. The resolution of the half-chiasma postulated by Holliday.

The progression is from the parental molecules (a), to the breakage and transfer of single strands (b), to the same configuration as in (b) presented in a different geometric form (c), to subsequent breakage of two of the four strands (d, left and right), with the consequence of nonexchange or exchange of flanking markers (e, left and right). After PotTER and DressLER, (12). reported a range of associated recombination from $18 \%$ to $66 \%$ in a number of Saccharomyces hybrids involving conversion at the arg 4 locus. They nevertheless continued to adhere to their view that the precursor is the same for both conversion and crossing over.

Studies of recombination in vegetative cells of yeast $(13,14)$ were interpreted to mean that gene conversion occurred in only one or the other of the two chromatids (duplexes) and therefore that asymmetry was the predominant phase. Moreover, it was suggested that the event that accounted for the heteroduplex was a transformation-like exchange of material from a donor duplex to a recipient homolog. In the MesELSONRADDING model this could be attained if the invading strand were cut and incorporated in the recipient duplex. The evidence in vegetative cells was obtained from sectored colonies in which all of the products of one class of conversion event were captured in the two halves of the sector. As in meiosis, the absence or rarity of certain types of sectored colonies that would be expected from a strict interpretation of the Holliday model was important in opting for asymmetry. Recom. bination of outside markers was regarded as a separate event occurring in the region of the conversional event because specific pairing in that region favored both (10). Although it should be emphasized that the molecular events in meiosis, as regards conversion and crossing over, can be very different from those in vegetative cells, there are a sufficient number of similarities between the two sets of data to warrant the suggestion that the fundamental mechanisms are the same for both.

\section{EXPERIMENTAL SYSTEM AND METHODOLOGY}

Diploids of Saccharomyces cerevisiae were chosen that were heterozygous for markers on chromosome VII, as shown in Figure 2, and heteroallelic for ade6, for two or more mutant sites. The distances in centimorgans are taken from MORTIMER and HAWTHORNE (11) except for the distance between ade6 and cly 8 which was calculated from the data derived from this study. It should be noted that the fermentation markers, $S U C$ and $M A L$, are unlinked to $c l y 8$ and are arbitrarily placed in the order $S U C M A L$ 

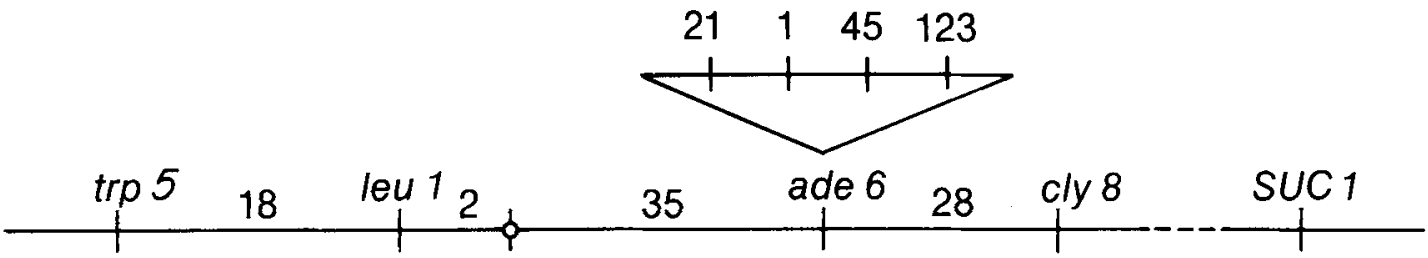

Figure 2. Genetic map of chromosome VII markers used in the experiments.

The symbols $\operatorname{trp} 5$, leul, ade6 represent requirements for tryptophan, leucine, and adenine, respectively; cly 8 represents a cell lysis mutation that manifests itself at $35^{\circ} \mathrm{C}$ and not at room temperature; $S U C l$ and $M A L I$ (not shown) are co-dominants for sucrose and maltose fermentation, respectively, and segregate as alleles. The dashed line indicates nonlinkage between the fermentation markers and $c l y 8$. The four alleles of ade6 are shown in the inverted triangle in their order relative to the centromere.

although they behave in segregation as alleles. The genotypes of the diploids are shown in Table I.

Gene conversions at the ade6 locus were obtained as prototrophs on adenineless medium. The prototrophs were induced by $\mathrm{x}$-rays, ultraviolet light, or arose spontaneously. The rates of induced conversion are given in Table II for the various heteroallelic combinations. The spontaneous convertants were obtained as follows: The diploids that were plated on adenineless medium for convertants were also plated on complete synthetic medium as controls to determine survival rates. The control plates, of untreated diploids, were then replica-plated on adenineless medium. Colonies that arose on the adenineless plates were therefore independent convertants. The frequency of spontaneous conversion was not determined.

The aim of further analysis was to determine

Table I.

The genotypes, with reference to each of the two homologs, of the seven diploids of these experiments.

\begin{tabular}{|c|c|c|c|c|c|c|c|c|}
\hline \multirow{3}{*}{ Culture } & \multirow{3}{*}{$\begin{array}{l}\text { ADE6 } \\
\text { Alleles }\end{array}$} & \multicolumn{7}{|c|}{ GENOTYPE } \\
\hline & & $T R P$ & $L E U$ & $A D E$ & $C L Y$ & & SUC & $M A L$ \\
\hline & & -1 & 10 & 1 & 1 & III & -1 & 1 \\
\hline \multirow[t]{2}{*}{$\mathrm{C} 819$} & +45 & - & + & +- & + & & + & - \\
\hline & $1+$ & + & - & -+ & - & & - & + \\
\hline \multirow[t]{2}{*}{$\mathrm{C} 821$} & $\underline{21+}$ & - & + & -+ & + & & + & - \\
\hline & +1 & + & - & +- & - & & - & + \\
\hline \multirow[t]{2}{*}{$\mathrm{C} 825$} & +123 & - & + & +- & + & & + & - \\
\hline & $21+$ & + & - & -+ & - & & + & - \\
\hline \multirow[t]{2}{*}{$\mathrm{C} 907$} & $21+123$ & - & + & -+- & + & & - & + \\
\hline & $+1+$ & + & - & +-+ & - & & + & - \\
\hline \multirow[t]{2}{*}{ C908 } & $21+123$ & - & + & -+- & + & & - & + \\
\hline & $+45+$ & + & - & +-+ & - & & + & - \\
\hline \multirow[t]{2}{*}{$\mathrm{C} 830$} & $21++123$ & - & + & -++- & + & & - & + \\
\hline & $+145+$ & + & - & +--+ & - & & - & + \\
\hline \multirow[t]{2}{*}{ C915 } & $21+45+$ & - & + & -+-+ & + & & + & - \\
\hline & $+1+123$ & + & - & +-+- & - & & - & + \\
\hline
\end{tabular}


Table II.

The rates of conversion to prototrophy, induced by $x$-rays and ultraviolet light, for different combinations of alleles, and the amount of recombination associated with these prototrophs. See text for particulars.

\begin{tabular}{|c|c|c|c|c|c|}
\hline $\begin{array}{l}A D E 6 \\
\text { Alleles }\end{array}$ & Treatment & $\begin{array}{l}\text { Prototrophs } \\
\text { Per } 10^{6}\end{array}$ & $\begin{array}{l}\text { Induced } \\
\text { Per } 10^{6}\end{array}$ & \multicolumn{2}{|c|}{$\begin{array}{c}\text { Associated } \\
\text { Recombination }\end{array}$} \\
\hline $1+$ & $\mathrm{X}$-ray 0 rads & 8 & - & & \\
\hline+45 & $3000 \mathrm{rads}$ & 349 & 341 & $15 / 67$ & $22 \%$ \\
\hline $21+$ & $"$ & 14 & - & & \\
\hline+1 & & 916 & 902 & $68 / 560$ & 241 \\
\hline $21+$ & $»$ & 8 & - & & \\
\hline+1 & & 790 & 782 & $19 / 96$ & 20 \\
\hline $21+$ & $"$ & 19 & - & & \\
\hline+123 & & 1052 & 1033 & $19 / 61$ & 31 \\
\hline $21+$ & $"$ & 24 & - & & \\
\hline+123 & & 854 & 830 & $15 / 69$ & 22 \\
\hline $1+$ & UV 0 ergs & 10 & - & & \\
\hline+45 & $400 \mathrm{ergs} / \mathrm{mm}^{2} / \mathrm{sec}$ & 310 & 300 & $16 / 98$ & 16 \\
\hline $21+$ & $"$ & 19 & - & & \\
\hline+1 & & 476 & 457 & $30 / 99$ & 30 \\
\hline $21+123$ & $\mathrm{X}$-ray 0 rads & 1 & - & & \\
\hline$+1+$ & 3000 rads & 87 & 86 & $79 / 560$ & 281 \\
\hline$\underline{21+123}$ & $»$ & 2 & - & & \\
\hline$+45+$ & & 33 & 31 & $48 / 560$ & 171 \\
\hline $21++123$ & $»$ & 0.46 & - & & \\
\hline$+145+$ & & 24.41 & 24 & $14 / 92$ & 15 \\
\hline $21+45+$ & $»$ & 0.36 & - & & \\
\hline$+1+123$ & & 1.86 & 1.5 & $38 / 94$ & 40 \\
\hline
\end{tabular}

1From homozygosis of fermentation markers.

the genotype of the diploid convertant with reference to each of the two homologs. Since all of the genes except the fermentation markers are linked, tetrad analysis of asci from the diploid convertant could in principle lead to the reconstruction of the diploid after conversion had occurred. It turned out that eight asci from each diploid were sufficient to determine the genotype unequivocally in all but a few cases. It is also of some interest to note that the doses of $\mathrm{x}$-rays and ultraviolet light used in these experiments had no effect on survival in the diploids but also produced almost no lethality in the dissections.
One or two cases gave no or very few viable spores among the dissections, and there were a few cases of only two spores surviving. Asci with four viable spores were the rule. It should also be noted that there were a few instances, comprising two or three percent of the total, of mosaic diploids which gave two or more genotypes from the same set of dissections. These exceptions are most likely cases of cells in which conversion to prototrophy occurred in both duplexes, yielding daughter cells of differing genotypes immediately after plating. Colonies with three genotypes were quite rare and could 
have a variety of explanations. At any rate, only colonies with a single genotype are included in the tabulations.

Since the fermentation markers are unlinked to $c l y 8$, the position of $S U C$ and $M A L$ cannot be unequivocally placed by tetrad analysis. Their position can however be ascertained by mitotic recombination. The procedure is as follows: $c l y 8$ is made homozygous by recombination stimulated by a non-lethal dose of either $\mathrm{x}$-rays or UV. In the absence of crossing over in region III, (see Figure 3a), the fermentation marker associated with cly 8 will also become homozygous. Thus, if SUC is on the same chromosome as cly 8 in the diploid being tested, homozygosis will produce a diploid that is cly $8 / \operatorname{cly} 8 \mathrm{SUC} / S U C$. Of 140 diploids tested, including representative genotypes of different classes, induced or spontaneous, only one was due to an exchange in region III. Thus, the genotypes for each homolog could be ascertained with considerable accuracy for all the markers in the diploid.

\section{EXPERIMENTAL RESULTS AND DISCUSSION}

The types of recombinants expected from exchanges in regions I, II, and III, associated with conversion of one or the other of the ade6 alleles, are shown in Figures 3 and 4. Figure $3 b$ and e represent symmetric (HoLliday) exchange of single strands between the two homologs. Figure $3 \mathrm{c}, \mathrm{d}$, f and $\mathrm{g}$ represent asymmetric strand transfer prior to isomerization in the MESELSONRADDING model. It is assumed, in Figure 4, that prototrophic conversion is occurring only in the asymmetric phase. This simplifying assumption accommodates most of the cases that were found. The cases that do not fit in these categories are nevertheless very important in the

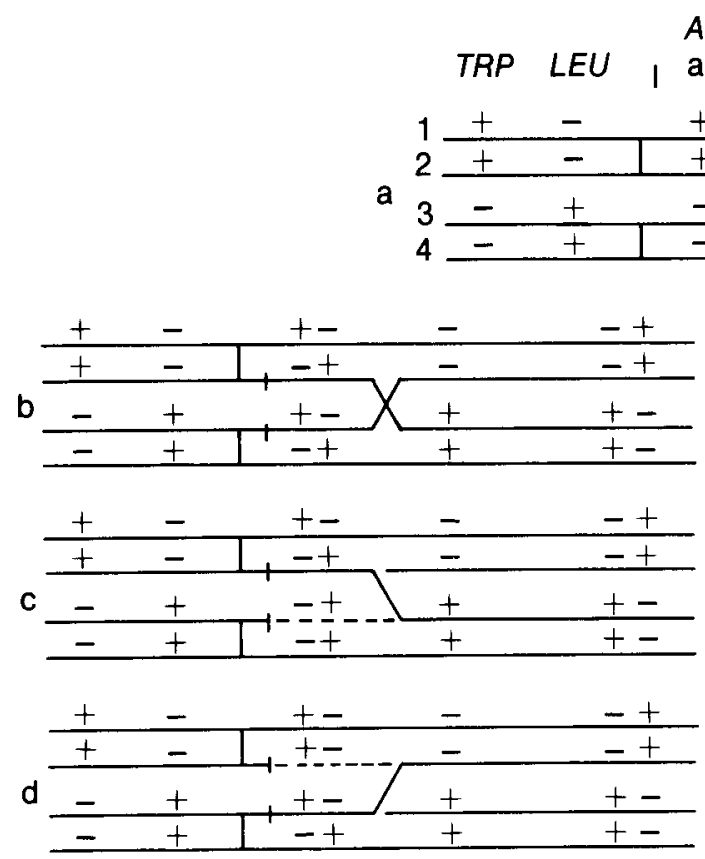

$A D E$

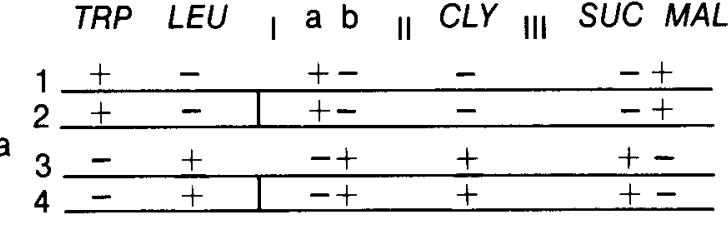

Figure 3. (a) Two DNA duplexes having the gene distribution as in C821 (Table I).

The vertical line connecting the strands of each duplex is the centromere. I, II and III denote regions between the centromere and the $A D E 6$ locus, between the $A D E 6$ locus and $C L Y 8$ and between $C L Y 8$ and the fermentation markers $S U C$ and $M A L$, respectively. The numbers 1, 2, 3, and 4 mark the chromatids that are formed after DNA replication and, in the absence of crossing over to the left of the centromere, segregate in mitosis as follows: 1 with 3 and 2 with 4 as one option, and 1 with 4 and 2 with 3 as the other. (b, e) The same duplexes after symmetrical exchange in regions I and II. The small vertical lines indicate points of breakage in the single strands of each duplex, as in the Holliday model. (c, $d, f, g$ ) Represent single strand invasions from regions I and II, to start the asymmetric phase of the MESELSON-RADDING model. 
interpretations that they provoke; they will be discussed in their proper context.

Implicit in Figure 3 is the interpretation that the formation of heteroduplexes can occur in the 2-chromatid stage preceding DNA replication. The cells that were used in this study were in stationary phase, namely, in G1. Esposito (2) and FABRE (3) have demonstrated conclusively

\section{Table III.}

The classes of prototrophs induced by $\mathrm{x}$-rays in $\mathbf{2}$-allele combinations. The genotypes are given as noncrossovers (nco) and crossovers (co) in regions I, II, III, or a combination of these. Allelic tests of the segregants that provided the data in this table were made in following manner: Each segregant was crossed with strains carrying one or the other of the two alleles in the parent diploid. The resulting diploid was sporulated to increase the frequency of conversion (conversion in meiosis is much higher than in mitosis) and the meiotic products were plated on adenineless medium. The results were consistent and unequivocal. Segregants that carried $c l y 8$ failed to grow at $35^{\circ}$. Tests for $\operatorname{trp} 5$ and leul were done on dropout media and fermentation tests to indicate the presence of $S U C$ and $M A L$ were done on diagnostic color plates. The meaning of asymmetric, symmetric, and uncertain is given in the text.

\begin{tabular}{|c|c|c|c|c|c|c|c|c|c|}
\hline \multirow[b]{2}{*}{$\begin{array}{l}A D E 6 \\
\text { Alleles }\end{array}$} & \multicolumn{3}{|c|}{ Asymmetric } & \multicolumn{3}{|c|}{ Symmetric } & \multicolumn{2}{|c|}{ Uncertain } & \multirow[b]{2}{*}{$\begin{array}{l}\text { Total } \\
\text { Cases }\end{array}$} \\
\hline & Genotype & No. & $\%$ co & \pm & $\frac{t+}{t+}$ & $\%$ co & No. ${ }^{1}$ & $\%$ co & \\
\hline \multirow{8}{*}{$\frac{1+}{+45}$} & & & & & & & $a b$ & & \\
\hline & nco & 52 & & 1 & 0 & & 00 & & \\
\hline & $\operatorname{coI}$ & 2 & & 0 & 0 & & 10 & & \\
\hline & II & 4 & & 1 & 0 & & 35 & & \\
\hline & III & 1 & & 0 & 0 & & 12 & & \\
\hline & $1, \mathrm{II}$ & 0 & & 0 & 0 & & 10 & & \\
\hline & I, III & 0 & & 0 & 0 & & 10 & & \\
\hline & & $\overline{59}$ & 12 & $\overline{2}$ & $\overline{0}$ & 50 & 7 & 100 & 67 \\
\hline \multirow{6}{*}{$\frac{21+}{+1}$} & nco & 78 & & 0 & 0 & & 00 & & \\
\hline & $\operatorname{coI}$ & 3 & & 0 & 0 & & 00 & & \\
\hline & II & 5 & & 1 & 2 & & 23 & & \\
\hline & III & 2 & & 0 & 0 & & 11 & & \\
\hline & I, II & 1 & & 0 & 0 & & 10 & & \\
\hline & & $\overline{89}$ & 13 & $\overline{1}$ & $\overline{2}$ & 100 & 4 & 100 & 96 \\
\hline \multirow{6}{*}{$\frac{21+}{+123}$} & nco & 92 & & 4 & 0 & & 00 & & \\
\hline & $\operatorname{coI}$ & 12 & & 0 & 0 & & 30 & & \\
\hline & II & 8 & & 5 & 2 & & 15 & & \\
\hline & III & 1 & & 0 & 0 & & 22 & & \\
\hline & $\mathrm{I}, \mathrm{II}$ & 0 & & 0 & 0 & & 10 & & \\
\hline & & $\overline{113}$ & 19 & $\overline{9}$ & $\overline{2}$ & 64 & 7 & 100 & 130 \\
\hline TOTALS & & 261 & 15 & 12 & 4 & 69 & 18 & 100 & 293 \\
\hline
\end{tabular}

1

$a$ assumes asymmetry; $b$ assumes symmetry 
Table IV.

The classes of prototrophs induced by ultraviolet light. See Table III for an explanation of testing procedures, and the meaning of symbols and terms.

\begin{tabular}{|c|c|c|c|c|c|c|c|c|c|}
\hline \multirow{2}{*}{$\begin{array}{l}A D E 6 \\
\text { Alleles }\end{array}$} & \multicolumn{3}{|c|}{ Asymmetric } & \multicolumn{3}{|c|}{ Symmetric } & \multicolumn{3}{|c|}{ Uncertain } \\
\hline & Genotype & No. & $\%$ co & \pm & $\frac{t+}{+t}$ & $\%$ co & No. 1 & $\%$ co & $\begin{array}{l}\text { Total } \\
\text { Cases }\end{array}$ \\
\hline$\frac{1+}{+45}$ & $\begin{array}{l}\text { nco } \\
\text { col } \\
\quad \text { II } \\
\text { I, II }\end{array}$ & $\begin{array}{r}83 \\
1 \\
8 \\
1 \\
93\end{array}$ & 12 & $\begin{array}{l}1 \\
0 \\
1 \\
0 \\
\frac{0}{2}\end{array}$ & $\begin{array}{l}0 \\
0 \\
0 \\
0 \\
\end{array}$ & 50 & $\begin{array}{ll}a & b \\
0 & 0 \\
2 & 3 \\
1 & 0 \\
0 & 0 \\
& \end{array}$ & 100 & 07 \\
\hline$\frac{21+}{+1}$ & $\begin{array}{l}\text { nco } \\
\text { coI } \\
\text { II } \\
\text { III } \\
\text { I, II }\end{array}$ & $\begin{array}{r}75 \\
6 \\
12 \\
1 \\
2 \\
\end{array}$ & & $\begin{array}{l}1 \\
0 \\
2 \\
0 \\
0 \\
\end{array}$ & $\begin{array}{l}0 \\
0 \\
0 \\
0 \\
0\end{array}$ & & $\begin{array}{ll}0 & 0 \\
0 & 0 \\
1 & 5 \\
0 & 0 \\
4 & 0\end{array}$ & & \\
\hline & & $\overline{96}$ & 24 & $\sqrt{3}$ & $\overline{0}$ & 67 & 5 & 100 & 104 \\
\hline TOTALS & & 189 & 18 & 5 & 0 & 60 & 8 & 100 & 201 \\
\hline
\end{tabular}

${ }^{1} a$ assumes asymmetry; $b$ assumes symmetry

that conversion can take place in G1. Thus the representation of two chromatids (each a DNA duplex) is valid. If the two heteroduplexes are formed in the way that was postulated by HoLLIDAY, the half-chiasma can be resolved by breakage of the single strands that are involved in the half-chiasma and or by breakage of the single strands that are involved in the half chiasma and or by breakage of the non-involved strands at the same level (refer to Figure 1). It can also be resolved by the ensuing replication. Resolution by breakage or by replication yields both recombinants and nonrecombinants.

Tables III-V present data of prototrophs induced by $\mathrm{x}$-rays and ultraviolet light, and of spontaneous origin, respectively, for diploids heteroallelic for two mutant alleles. The data are presented in three general classes, asymmetric, symmetric, and uncertain. In the asymmetric column are those cases for which there is no need to assume two heteroduplexes in the region of hybrid DNA. The symmetric column includes cases which must have had two heteroduplexes at the sites of conversion according to either the Holliday or the Meselson-Radding model.
This is certainly true of the $++/++$ cases but it would also be true for the $++/--$ even if some of these were due to reciprocal recombination between the alleles. The uncertain cases (Table IV) are those which are not to be found among the classes derived from $\mathrm{C} 819$ and $\mathrm{C} 825$ (Figure 4), nor among a similar set of classes from C821 (not shown). All are recombinant for distal markers. If they had had an asymmetric origin, it would have to be assumed that several of the cases, those with crossovers in more than one region (Table VI), involved crossing over at the four-chromatid stage (during or after DNA replication). Alternatively, all of the uncertain cases can be accounted for quite simply if symmetry is invoked and if repair in one or both heteroduplexes is accompanied by the recombinant type of resolution. The number in this category is small and would not have an important impact on the numerically much larger class of presumed asymmetrics. If their origin were symmetric, however, they would add importantly to this class.

The comparison of asymmetrics with symmetrics with respect to crossing over in Table III is 
Table V.

The classes of spontaneous prototrophs. See Table III for an explanation of testing procedures, and the meaning of symbols and terms. At the bottom of the table, for comparison with the 2 -allele diploids, the data are given for the classes of prototrophs obtained from a 4-allele diploid. All four alleles were tested for by the method described in Table III.

$A D E 6$

Alleles

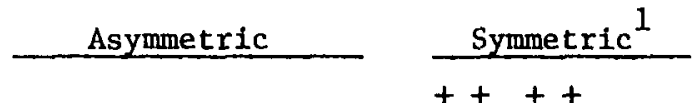

Uncertain

Genotype №. \% co $\frac{t+t+}{t-t+} \%$ co

No. ${ }^{2} \%$ co $\begin{array}{r}\text { Total } \\ \text { Cases }\end{array}$

$\frac{21+}{+123}$

nco

$\operatorname{coI}$

29

II

7

20

$a b$

00

20

02

III

15

00

00

I, II

1

72

00

$\frac{1}{53}$

47

$0 \quad 0$

82

2 100

64

\section{$\frac{21+}{+1}$}

nco

50

10

II 17

17
0

$\overline{9} \quad \overline{2}$

00

00

13

$\begin{array}{ll}\text { III } & 0 \\ \text { I, II } & 4\end{array}$

00

4
0

I, III

$$
\overline{81}
$$

$134 \quad 45$

133

69

20

00

40

उ 100

89

TOTAL

$\frac{21+t 123}{t 145 t}$

\begin{tabular}{lr} 
nco & 65 \\
coI & 3 \\
II & 10 \\
III & 2 \\
& \\
\cline { 2 - 2 } & 80
\end{tabular}

65

3

10

80

19

$\begin{array}{r}7 \\ 0 \\ 8 \\ 0 \\ \hline 15\end{array}$

0

0

0

0

$53 \quad 0$

94

${ }^{1}$ Prototrophs from $\frac{21++123}{+145+}$ were:

nco: $\frac{t+t+}{t+t-}(4), \frac{t+t+t}{-t--}(1), \frac{t+t+}{-t+t}(1), \frac{t+t+}{t---}(1)$.

$$
\text { co: } \frac{t+t+}{t+t-}(1), \frac{t+t+}{t+t+}(2), \frac{t+t+t}{t-t-}(1), \frac{t+t+}{t---}(2), \frac{t+t+t}{---t}(1), \frac{t+t+}{---}
$$

Number of cases in parentheses. 
Table VI.

The genotypes of the "uncertain “ cases obtained from $x$-rays, ultraviolet light, and spontaneously. See text for details.

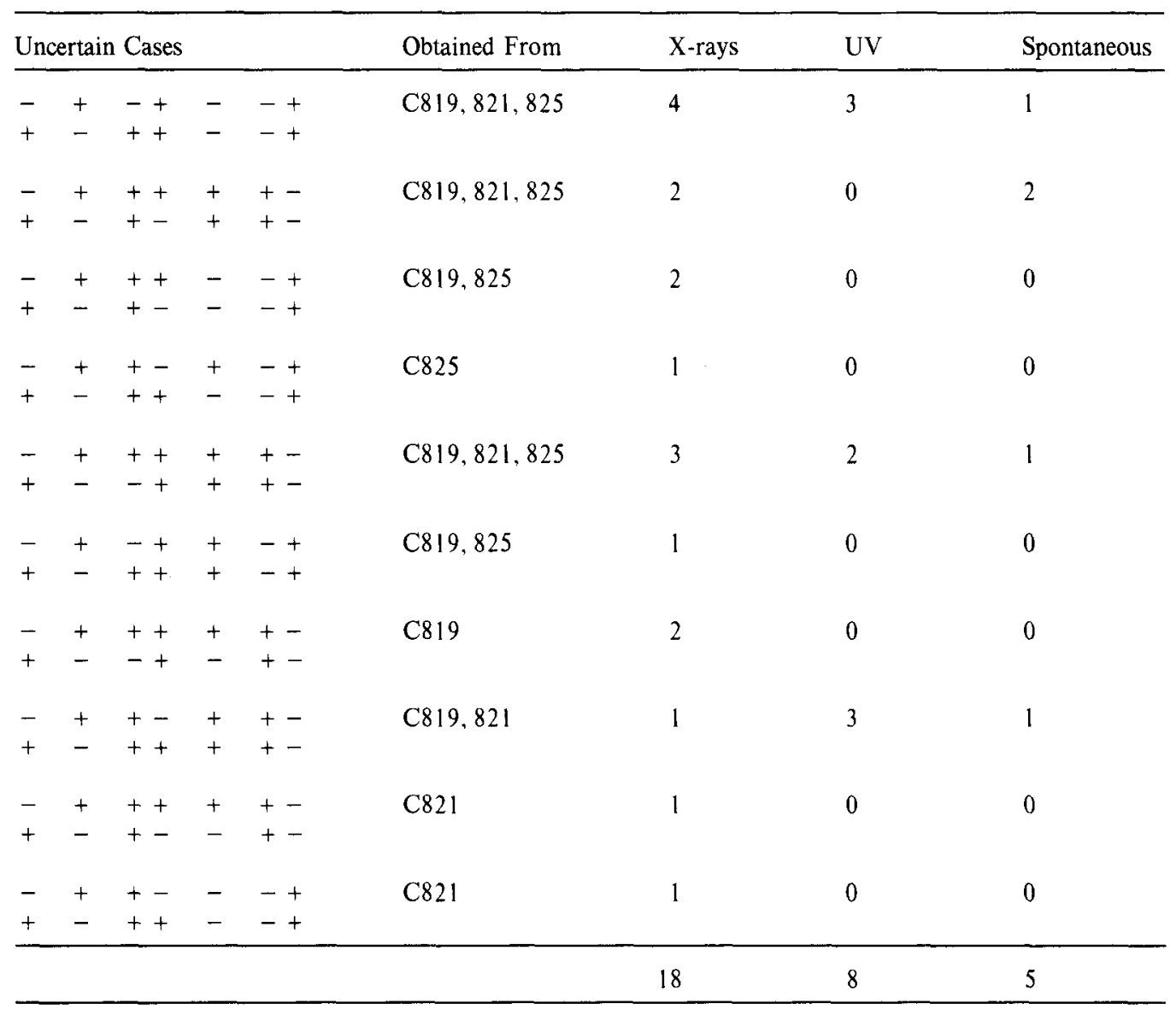

striking. There were $15 \%$ crossovers among 261 asymmetrics and $69 \%$ among 16 symmetrics, exclusive of the uncertains. Similar results are obtained with ultraviolet light (Table IV). The relationship also seems to hold for the spontaneous prototrophs although for these the asymmetric class shows a much higher percent of recombinants than those that were induced (Table V). Here again, however, the symmetric class includes more recombinants than the asymmetric class. The numbers are small for both induced and spontaneous prototrophs, but taken in the aggregate they are consistent in showing a much higher frequency of recombination of outside markers than the asymmetrics.
The question of whether the symmetrics, of genotype $++1--$ at the ade6 locus, are attributable to crossing over between alleles or to heteroallelic repair can be tentatively answered by the following analysis. If the parental genotype is

$$
\frac{-+t_{-}++-}{+-\frac{1}{+}-+}
$$

a crossover between alleles would produce a prototroph of genotype

$$
\frac{-+{ }_{0}+-}{+-+}++\frac{+}{-}
$$


Repair to prototrophy without crossing over would give either of two results, as follows:

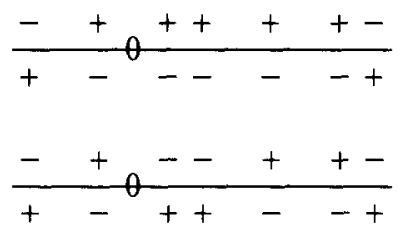

Repair accompanied by a cross over in region II (the only region implicated in Tables III-V) would yield:

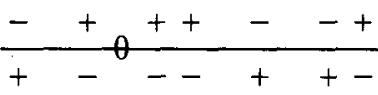

and

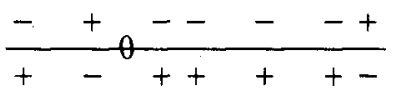

and the corresponding homozygotes, such as:

and

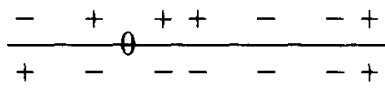

$\frac{-+0++++-}{+-0+-++-}$

The results of this analysis are given in Table VII. Two points need to be made in interpreting this table. One is that C821 has a reverse order of adenine alleles with respect to other markers on the same chromosome (see Table I) and a suitable correction has been made in presenting the data. It should be noted, secondly, that one of the repair crossover classes is identical with the class expected from a crossover between the adenine alleles. Its frequency should be equal to that of the companion class and if it is found in substantial excess, as it is (12 to 1 , not shown in Table VII), the indications are that crossing over between alleles does occur quite frequently. However, even if all 12 cases are due to crossing over between the adenine alleles, the frequency of crossing over among those cases that are the consequence of repair amounts to 39 percent. If one takes into account the $++1++$ recombinants and the results obtained with four alleles at the ADE6 locus, arranged in two different ways, (Tables V and IX), in which a simple crossover
Table VII.

The analysis of symmetric prototrophs from diploids heteroallelic for two alleles. See text for details.

\begin{tabular}{|c|c|c|c|}
\hline & \multicolumn{2}{|c|}{ Repair } & $\begin{array}{l}\text { Putative } \\
\text { co between } \\
\text { Alleles }\end{array}$ \\
\hline$X$-ray & 5 & 1 & 6 \\
\hline UV & 2 & 0 & 3 \\
\hline Spontaneous & 4 & 6 & 3 \\
\hline TOTAL & 11 & 7 & 12 \\
\hline
\end{tabular}

between alleles cannot result in a prototroph and therefore repair must be invoked, the increase in recombination among symmetrics as compared to asymmetrics appears unmistakable.

Figure 4 lists 26 classes of which two are noncrossovers and 24 are crossovers. These include $584 / 647$, or $90 \%$, of the 2-allele prototrophs. The other $10 \%$ are symmetrics and uncertains. Among the 20 crossover classes (3a) and $(5 b)$ are duplicates as are (3b) and (5a). Classes (9a) and ( $1 b)$ and (9b) and (la) are also duplicate classes but since $(9 a)$ and $(9 b)$ are double crossovers and are therefore rare, these will not be discussed further. However a comparison of some interest can be made among the other duplicate classes. In the 647 cases obtained from the 2-allele prototrophs, the markers to the left of the centromere (with two exceptions in which $L E U$ became homozygous) remain in heterozygous condition as they were in the parental genotype. Segregation of the chromatids in mitotic division is generally assumed to be random in the sense that two sister centromeres separate from each other and go to the pole with either of the homologous sister centromeres. Thus, referring to Figure 3,1 goes with 3 and 2 goes with 4 or 1 goes with 4 and 2 with 3 . These segregations are assumed to be equally probable. Returning to Figure 4 , (3a) should be equal to $(2 a),(3 b)$ to $(2 b),(5 a)$ to $(4 a)$, and (5b) to (4b). Thus, the duplicate classes, (3a) $+(5 b)+(3 b)+(5 a)$ should be numerically equal to their identifiable counterparts, $(2 \mathrm{a})+$ $(2 b)+(4 a)+(4 b)$. Table VIII shows that this is not the case. Those segregations that can be unambiguously classified as crossovers in I and 


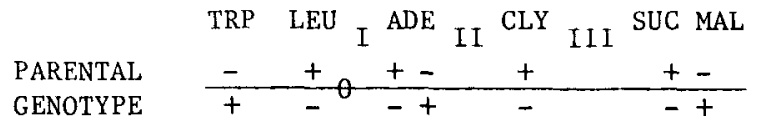

\section{PROTOTROPH DERIVATIVES}

\begin{tabular}{|c|c|c|c|c|c|c|c|c|c|c|c|}
\hline (1a) nco & $\bar{t}$ & $\begin{array}{l}+ \\
-\end{array}$ & $\begin{array}{l}++ \\
-+\end{array}$ & $\begin{array}{l}+ \\
-\end{array}$ & $\begin{array}{l}+- \\
-+\end{array}$ & $(1 \mathrm{~b})$ & $\overline{+}$ & $\begin{array}{l}+ \\
-\end{array}$ & $\begin{array}{l}+- \\
++\end{array}$ & + & $\begin{array}{l}+- \\
-+\end{array}$ \\
\hline (2a) $\operatorname{coI}$ & $\overline{+}$ & $\begin{array}{l}+ \\
-\end{array}$ & $\begin{array}{l}-+ \\
++\end{array}$ & $\begin{array}{l}- \\
+\end{array}$ & $\begin{array}{l}-+ \\
+-\end{array}$ & $(2 b)$ & $\overline{+}$ & $\begin{array}{l}+ \\
-\end{array}$ & $\begin{array}{l}++ \\
+-\end{array}$ & t & -+ \\
\hline (3a) & $\overline{+}$ & $\begin{array}{l}+ \\
-\end{array}$ & $\begin{array}{l}+- \\
++\end{array}$ & $\begin{array}{l}+ \\
+\end{array}$ & $\begin{array}{l}+- \\
+-\end{array}$ & $(3 b)$ & $\overline{+}$ & $\begin{array}{l}+ \\
-\end{array}$ & $\begin{array}{l}++ \\
-+\end{array}$ & - & $\begin{array}{l}-+ \\
-+\end{array}$ \\
\hline (4a) $\operatorname{colI}$ & - & $\begin{array}{l}+ \\
-\end{array}$ & $\begin{array}{l}++ \\
-+\end{array}$ & $\dot{+}$ & $\begin{array}{l}-+ \\
+-\end{array}$ & $(4 b)$ & - & $\begin{array}{l}+ \\
-\end{array}$ & $\begin{array}{l}+- \\
++\end{array}$ & - & $\begin{array}{l}-+ \\
+-\end{array}$ \\
\hline$(5 a)$ & $\dot{-}$ & $\begin{array}{l}+ \\
-\end{array}$ & $\begin{array}{l}++ \\
-+\end{array}$ & - & $\begin{array}{l}-+ \\
-+\end{array}$ & $(5 b)$ & $\dot{-}$ & $\begin{array}{l}+ \\
-\end{array}$ & $\begin{array}{l}+- \\
++\end{array}$ & $\begin{array}{l}+ \\
+\end{array}$ & $\begin{array}{l}+- \\
+-\end{array}$ \\
\hline (6a) $\operatorname{col} I I$ & - & $\begin{array}{l}+ \\
-\end{array}$ & $\begin{array}{l}++ \\
-+\end{array}$ & $\begin{array}{l}+ \\
-\end{array}$ & $\begin{array}{l}-+ \\
+-\end{array}$ & $(6 b)$ & $\dot{+}$ & $\begin{array}{l}+ \\
-\end{array}$ & $\begin{array}{l}+- \\
++\end{array}$ & $\begin{array}{l}+ \\
-\end{array}$ & $\begin{array}{l}-+ \\
+-\end{array}$ \\
\hline$(7 a)$ & - & $\begin{array}{l}+ \\
-\end{array}$ & $\begin{array}{l}++ \\
-+\end{array}$ & $\begin{array}{l}+ \\
-\end{array}$ & $\begin{array}{l}-+ \\
-+\end{array}$ & $(7 b)$ & $\overline{+}$ & $\begin{array}{l}+ \\
-\end{array}$ & $\begin{array}{l}+- \\
++\end{array}$ & $\begin{array}{l}+ \\
-\end{array}$ & $\begin{array}{l}+- \\
+-\end{array}$ \\
\hline (8a) $\begin{aligned} \operatorname{coI} \\
+I I\end{aligned}$ & $\bar{t}$ & $\begin{array}{l}+ \\
-\end{array}$ & $\begin{array}{l}-+ \\
++\end{array}$ & $\begin{array}{l}+ \\
-\end{array}$ & $\begin{array}{l}+- \\
-+\end{array}$ & $(8 b)$ & $\overline{+}$ & $\begin{array}{l}+ \\
-\end{array}$ & $\begin{array}{l}++ \\
+-\end{array}$ & $\begin{array}{l}+ \\
-\end{array}$ & $\begin{array}{l}+- \\
-+\end{array}$ \\
\hline (9a) & $\overline{+}$ & $\begin{array}{l}+ \\
-\end{array}$ & $\begin{array}{l}+- \\
++\end{array}$ & $\begin{array}{l}+ \\
-\end{array}$ & $\begin{array}{l}+- \\
-+\end{array}$ & $(9 b)$ & $\overline{+}$ & $\begin{array}{l}+ \\
-\end{array}$ & $\begin{array}{l}++ \\
-+\end{array}$ & $\begin{array}{l}+ \\
-\end{array}$ & $\begin{array}{l}+- \\
-+\end{array}$ \\
\hline $\begin{array}{r}(10 a) \operatorname{coI} \\
+ \text { III }\end{array}$ & - & $\begin{array}{l}+ \\
-\end{array}$ & $\begin{array}{l}-+ \\
++\end{array}$ & - & $\begin{array}{l}+- \\
-+\end{array}$ & $(10 b)$ & - & $\begin{array}{l}+ \\
-\end{array}$ & $\begin{array}{l}++ \\
+-\end{array}$ & $\bar{t}$ & $\begin{array}{l}+- \\
-+\end{array}$ \\
\hline (11a) & $\dot{+}$ & $\begin{array}{l}+ \\
-\end{array}$ & $\begin{array}{l}+- \\
++\end{array}$ & + & $\begin{array}{l}+- \\
-+\end{array}$ & (11b) & $\begin{array}{l}- \\
+\end{array}$ & $\begin{array}{l}+ \\
-\end{array}$ & $\begin{array}{l}++ \\
-+\end{array}$ & $\begin{array}{l}- \\
-\end{array}$ & $\begin{array}{l}+- \\
-+\end{array}$ \\
\hline $\begin{aligned}(12 a) & \operatorname{coII} \\
+ & \operatorname{III}\end{aligned}$ & - & $\begin{array}{l}+ \\
-\end{array}$ & $\begin{array}{l}++ \\
-+\end{array}$ & + & $\begin{array}{l}+- \\
-+\end{array}$ & (12b) & $\overline{+}$ & $\begin{array}{l}+ \\
-\end{array}$ & $\begin{array}{l}+- \\
-+\end{array}$ & $\begin{array}{l}- \\
+\end{array}$ & $\begin{array}{l}+- \\
-+\end{array}$ \\
\hline$(13 a)$ & + & $\begin{array}{l}+ \\
-\end{array}$ & $\begin{array}{l}++ \\
-+\end{array}$ & - & $\begin{array}{l}+- \\
-+\end{array}$ & (13b) & $\overline{+}$ & $\begin{array}{l}+ \\
-\end{array}$ & $\begin{array}{l}+- \\
++\end{array}$ & $\begin{array}{l}+ \\
+\end{array}$ & $\begin{array}{l}+- \\
-+\end{array}$ \\
\hline
\end{tabular}

Figure 4. The classes of prototrophs that are expected from asymmetric conversion, with or without crossing over in regions I, II and III.

The genes are distributed as in $\mathrm{C} 819$ and $\mathrm{C} 825$ (Table I). Note that (3a) and (5b) are duplicates, as are $(5 \mathrm{a})$ and $(3 b),(1 a)$ and $(9 b)$, and $(9 a)$ and $(1 b)$.

II are about twice as frequent as those in the duplicate classes. This may mean that random segregation of chromatids does not always occur or that the recombinational event is often completed in $\mathrm{Gl}$ with the consequence that (2a), $(2 b),(4 a)$ and $(4 b)$ are the preponderant classes in relation to their corresponding alternatives. If it turns out that neither explanation suffices, the interesting possibility arises that crossovers can also occur that are not associated with hybrid DNA but are instead due to double-strand breakages as noted below.

We have included 3-point and 4-point crosses for the purpose of assessing conversion and 
Table VIII.

A numerical comparison of unambiguous crossovers in regions $I$ and II with the duplicate classes (3a), (5b) and (3b), (5a), as depicted in Figure 4, in which a crossover in region $I$ is indistinguishable from a crossover in region II.

\begin{tabular}{|c|c|c|c|}
\hline & \multirow{2}{*}{$\begin{array}{c}\text { Duplicate } \\
\text { Classes } \\
\text { I or II }\end{array}$} & \multicolumn{2}{|c|}{ Unambiguous } \\
\hline & & I & II \\
\hline X-rays $30^{\prime \prime}$ & 8 & 17 & 9 \\
\hline UV $25^{\prime \prime}$ & 13 & 7 & 10 \\
\hline \multirow[t]{2}{*}{ Spontaneous } & 18 & 17 & 15 \\
\hline & 39 & 41 & 34 \\
\hline
\end{tabular}

associated recombination under conditions in which prototrophs can not be easily obtained from crossing over alone (Tables II, V and IX). As expected from the order of the alleles, the two 3 -point crosses gave rates of induced conversion that are much lower than those obtained from 2point crosses. The frequency of associated recombination was much the same as for 2-point crosses but was not measured in the same way. Prototrophs from 3-point crosses were analyzed, not by dissection, but by the frequency of homozygosis of the fermentation markers. On the assumption of random segregation of the chromatids, as discussed earlier, the frequency of homozygosis should be multiplied by a factor of two to correct for the fact that certain types of recombinants are not detectable. While this method of analysis is not as accurate nor as informative as the dissection method, the fact that similar frequencies were obtained suggests that the same parameters are operating.

The 4-point crosses are of two kinds, $21++$ $123 /+145+$ and $21+45+/+1+123$. Prototrophs are expected from the first type by excision-repair of the two middle alleles. Prototrophy of this kind should be much more frequent than that due to conversion of the two outside alleles, 21 and 123 to wildtype. In fact there were 68 instances of the former and two of the latter. The 4-point cross with alternating alleles give the lowest frequency of all combinations tested of induced prototrophs, the frequency being about 1.5 per $10^{6}$ cells plated per 3,000 rads of $x$-rays. This frequency is only about five times that of background and therefore the data include some contamination of spontaneous prototrophs. The production of a wild-type $(++++)$ gene from this combination of alleles requires two independent events within the gene. A variety of combinations of - alleles was found in the prototrophic diploid in the other chromatid. Again, those classes that were inferred to be symmetric have a higher frequency of associated recombination than those that were not.

Finally, if the Meselson-Radding model is interpreted explicitly, a Holliday-type cross configuration of single strands must occur between the two homologs at some point along their lengths. If the invasive strand can be cut without forming the cross-configuration, then not only would recombination of outside markers not occur but the result would be equivalent to interchromosomal transformation. An analysis of the asymmetric cases shows that the majority of such cases are nonrecombinant, at least in that part of the chromatid that lies between the centromere and the fermentation markers, a very long distance indeed if one judges distance from meiotic crossing over. When recombination does occur, it occurs most frequently in regions I and II, i.e., immediately around the locus of $A D E 6$. It is noteworthy that all 53 symmetric crossovers occur in region II. The conclusion is inviting that there may be two kinds of events, one that is asymmetric and is transformation-like to give a single region of hybrid DNA, by strand invasion as postulated by Meselson and RadDing. If that is the case, where do the recombinants come from? Possibly, as STADLER and Towe (16) also have suggested, they are derived principally from symmetric hybrid DNA. If that is so, many of the cases classified as asymmetric might actually be symmetric. But it is just as plausible to suppose that a second type of event, mentioned earlier, also plays a role, and that there are sequences in the DNA strands that dictate the simultaneous cutting of both strands in each of the two chromatids, with resulting recombination (a version of the findings of MESELSON and WeIgLE, (8)). Such a controlled utilization of nuclear "restriction" enzymes is not beyond reasonable expectations. 
Table IX.

The classes of prototrophs induced by $x$-rays from 4-allele diploids. See Table III for an explanation of testing procedures, and the meaning of symbols and terms.

Asymmetric

ADE 6

A1leles

$\frac{21++123}{+145+}$

nco
coI
II

nco
coI
II

nco
coI
II

Alleles Converted Sub-

$\underline{1,45}$ total \% co

21,123

2

0

3
Symmetric $^{1}$

$\begin{array}{rrrrr}68 & 70 & & 7 & \\ 2 & 2 & & 0 & \\ 1 & 4 & & 9 & \\ & \frac{76}{76} & 8 & \frac{16}{16} & 56\end{array}$

92

\begin{tabular}{clr}
$21+45+$ & nco & 28 \\
\hline$+1+123$ & coI & 6 \\
& II & 9 \\
& III & 1 \\
& I, III & 1
\end{tabular}

TOTALS

\begin{tabular}{rr}
27 & 55 \\
1 & 7 \\
7 & 16 \\
0 & 1 \\
0 & 1 \\
\hline &
\end{tabular}

$\begin{array}{rr} & 3 \\ & 0 \\ 11 \\ \\ \\ 33 \quad \frac{0}{14}\end{array}$

Cases

$\underline{21,45} \quad \underline{1,123}$

\section{3}

11

0

$\overline{14} \quad 79 \quad 94$

$1_{\text {Prototrophs from }} \frac{21++123}{+145+}$ were:

$$
\begin{aligned}
& \text { nco: } \frac{t+t+}{-+-}(2), \frac{t+t+}{t+t-}(1), \frac{t+t+t}{--t}(1), \frac{t+t+t}{--t-}(1), \frac{t+t+1}{+-t-}(1) \text {, } \\
& \frac{t+t+}{-t+t}(1) \\
& \text { co: } \frac{t+t+}{-++t}(2), \frac{t+t+}{--t}(1), \frac{t+t+}{t-t-}(2), \frac{t+t+t}{t+-t}(1), \frac{t+t+1}{t+t+} \text { (3). }
\end{aligned}
$$

Prototrophs from $\frac{21+45+}{+1+123}$ were:

$$
\begin{aligned}
& \text { nco: } \frac{t+t+}{-t--}(2), \frac{t+t+}{t+t-(1)} \\
& \text { co: } \frac{t+t+}{-t-}(1), \frac{t+t+}{t+t-}(1), \frac{t+t+}{-t+-}(2), \frac{t+t+t}{-t+}(3), \frac{t+t+}{-t+t} \text { (2), } \\
& \frac{t+t+t}{t+t+}(1), \frac{t+t+t}{t-t+1} \text { (1). }
\end{aligned}
$$

Number of cases in parentheses. 


\section{CONCLUDING REMARKS}

There have been several attempts to explain gene conversion and the relation of gene conversion to adjacent crossing over. The model presented by MESELSON and RADDING fits most, if not all, of the meiotic data. Three points are clear: gene conversion requires hybrid DNA as a precursor condition, as was predicted by HoLLIDAY (5). Convertants are produced by a repair mechanism, thought to be usually excisionrepair. Conversion is most often found in only one of the four meiotic products at a given locus. This asymmetry provides the genetic impetus for the Meseison-RADDing model.

Analogous genetic results have been obtained in vegetative cells. However, it is not so clear that vegetatively produced conversion can yield to a single unifying hypothesis. Evidence is presented that is interpreted as interchromosomal transformation, the transfer of a piece of single-stranded DNA from one duplex to its homolog. The Meselson-RAdDing model can be modified to account for this way of achieving asymmetry. Data are also presented that may turn out to mean that both strands of each duplex can be cut simultaneously to produce recombinants without attendant conversion. The same events may be occurring also in meiosis and escape detection. Thus conversion and crossing over may be separable depending on which of several mechanisms obtains. The difference that has been observed of the association of recombination with asymmetry as compared with symmetry is another indication that more than one mechanism is operating.

I feel deeply honored by being an awardee of the Emil Christian Hansen Foundation. If $\emptyset_{\mathrm{J}}$ VIND WINGE is regarded as the father of yeast genetics for his pioneering experiments in the mid-thirties, then EmIL Christian HaNSEN is the grandfather. All this started in Copenhagen, at the Carlsberg Laboratory.

\section{REFERENCES}

1. BeLl, L. \& B. Byers: Occurrence of crossed strand-exchange forms in yeast DNA during meiosis. Proc. Natl. Acad. Sci. USA 76, 34453449 (1979)

2. Esposito, M. S.: Evidence that spontaneous mitotic recombination occurs at the two-strand stage. Proc. Natl. Acad. Sci. USA 75, 44354440 (1978)

3. FABRE, $F .:$ Induced intragenic recombination in yeast con occur during the Gl mitotic phase. Nature 272, 795-797 (1978)

4. Fogel. S., R. Mortimer, K. Lusnak \& F. TAVARES: Meiotic gene conversion: a signal of the basic recombination event in yeast. Cold Spring Harbor Symp. Quant. Biol. 43, 1325-1341 (1979)

5. Holliday, R.: A mechanism for gene conversion in fungi. Genet. Res. 5, 282-304 (1964)

6. Hotchkiss, R. D.: Models of genetic recombination. Annu. Rev. Microbiol. 28, 445 (1974)

7. Hurst, D. D., S. Fogel \& R. K. Mortimer: Conversion-associated recombination in yeast. Proc. Natl. Acad. Sci. USA 69, 101-105 (1972)

8. Meselson, M. \& J. J. Weigle: Chromosome breakage accompanying genetic recombination in bacteriophage. Proc. Natl. Acad. Sci. 47, 857868 (1961)

9. Meselson, M. S. \& C. M. Radding: A general model for genetic recombination. Proc. Natl. Acad. Sci. USA 72, 358-361 (1975)

10. Mitchell, M. B.: Aberrant recombination of pyridoxine mutants of Neurospora. Proc. Natl. Acad. Sci. 41, 215-220 (1955)

11. Mortimer, R. K. \& D. C. Hawthorne: Genetic mapping in Saccharomyces. IV. Mapping of temperature-sensitive genes and use of disomic strains in localizing genes. Genetics $74,33-54$ (1973)

12. Potter, H. \& D. Dressler: DNA recombination: In vivo and in vitro studies. Cold Spring Harbor Symp. Quant. Biol. 43, 969-985 (1979)

13. Roman, H.: Studies of recombination in yeast. Stadler Genetics Symp. (University of Missouri, Columbia) 5, 35-48 (1973)

14. Roman, H.: Studies of recombination in vegetative cells of Saccharomyces cerevisiae. Israel J. Med. Sci. 8, 669-678 (1973)

15. Sigal, N. \& B. Alberts: Genetic recombination: The nature of a crossed strand-exchange between two homologous DNA molecules. J. Mol. Biol. 71, 789 (1972)

16. Stadler, D. R. \& A. M. Towe: Evidence for meiotic recombination in Ascobolus involving only one member of a tetrad. Genetics $68,401-$ $413(1971)$ 